\title{
Success and reliability of extrafemoral Exoseal vascular closure device: “Off-label” usage
}

\author{
ISMAIL CAYMAZ ${ }^{1,2, *}$, FUAD NURILI $^{3}$, OZLEM KOLCAK $^{4}$, OMER ARAS $^{5}$, BURCAK GUMUS $^{1}$ \\ ${ }^{1}$ Department of Interventional Radiology, Baskent Medical Faculty, Istanbul Training and Research Hospital, Istanbul, Turkey \\ ${ }^{2}$ Istanbul Medeniyet University Medical School, Goztepe Training and Research Hospital, Istanbul, Turkey \\ ${ }^{3}$ Department of Radiology, Weil Cornell Medical College, New York, NY, USA \\ ${ }^{4}$ Department of Interventional Radiology, Kartal Dr. Lutfi Kirdar Training and Research Hospital, Istanbul, Turkey \\ ${ }^{5}$ Department of Radiology, Memorial Sloan Kettering Cancer Center, New York, NY, USA \\ ${ }^{*}$ Corresponding author: Ismail Caymaz, MD; Istanbul Medeniyet University Goztepe Training and Research Hospital, Eğitim Mahallesi, Doktor \\ Erkin caddesi, 34722 Kadiköy, Istanbul, Turkey; Phone: +90 21656640 00; Mobile: +90 50635819 71; Fax: +90 21656666 14; \\ E-mail: dr.ismailcaymaz@gmail.com
}

(Received: October 8, 2017; Revised manuscript received: October 20, 2018; Second revised manuscript received: May 9, 2019; Accepted: July 7, 2019)

\begin{abstract}
Aim: The aim of this study is to present the reliability and efficacy of Exoseal vascular closure device (EVCD) for closure of extrafemoral punctures. Materials and methods: All patients who were treated with EVCD following arterial endovascular treatment involving an extrafemoral puncture between April 2013 and January 2014 were examined retrospectively. This study included 11 patients (4 women and 7 men between the ages of 48 and 87 years; average age $=65$ years). A total of 13 procedures were performed in 11 patients involving the following access routes: brachial artery $(n=5)$, popliteal artery $(n=4)$, and polytetrafluoroethylene graft $(n=4)$. Results: Twelve out of 13 EVCD procedures achieved technical success and procedural success. One minor and one major complications occurred. Both complications were revealed to be pseudoaneurysms, both in the brachial artery. Pseudoaneurysm of the minor complication was treated by Fibrin Sealant (Tisseel) injection guided by ultrasonography and the other pseudoaneurysm was treated by covered stent placement. Conclusions: The femoral artery is an essential access route of arterial endovascular procedures; however, in some cases, the extrafemoral arterial route is necessary. In this study, EVCD was found to be useful for closing extrafemoral arterial routes. This study had a limited number of cases and more large-scale studies are needed.
\end{abstract}

Keywords: endovascular treatment, vascular closure device, peripheral disease, vascular disease, interventional radiology

\section{Introduction}

Arterial access is the first step in arterial endovascular treatment. However, the arterial access route is also associated with the most frequent complications of arterial endovascular treatment. Therefore, the maintenance of hemostasis after arterial endovascular treatment is critical [1]. The gold standard for achieving the maintenance of hemostasis following extra femoral catheterization is manual compression. However, given the proliferation of vascular closure devices (VCDs) and their associated benefits of rapid hemostasis, VCDs have been applied to vascular sites as an alternative to manual compression. VCDs were first introduced in the 1990s [2]. Their reliability and success have been proven in many studies [3-5]. The Exoseal (VCD; Cordis Corporation, Bridgewater, NJ, USA) was introduced to the medical community in 2010 with the purpose of using them to close femoral arterial punctures. EVCD is based on the deployment of a polyglycolic acid plug in the extravascular area of the puncture site. This plug dissipates by turning into carbon dioxide and water $[1,2]$. The plug can be deployed through the procedural sheath (e.g., 5, 6, or $7 \mathrm{~F}$ sheath).

Extra femoral artery closure with VCDs can be implemented as a new interventional procedure. There is a limited data about extra femoral usage of VCDs. Pieper et al. [6] reported an initial study on using EVCD to achieve extrafemoral access site closure; in their study, EVCD was successful in 12 of 13 procedures.

In this paper, we aimed to summarize our experience using EVCD in patients who underwent arterial endovascular treatments where an extrafemoral entry was implemented. In light of the current lack of data on this

This is an open-access article distributed under the terms of the Creative Commons Attribution-NonCommercial 4.0 International License, which permits unrestricted use, distribution, and reproduction in any medium for non-commercial purposes, provided the original author and source are credited, a link to the CC License is provided, and changes - if any - are indicated. 
subject in the literature, we believe this paper will be useful in spite of our limited cases.

\section{Materials and Methods}

\section{Patient population}

All 11 patients who underwent arterial endovascular treatment with EVCD deployment between April 2013 and January 2014 were retrospectively included in this study. Each patient's medical history, procedure, and follow-up features were recorded. The study was approved by the Ethics Committees.

\section{Interventional procedure}

All procedures were performed by two interventional radiologists who also had experience in using EVCD. We used Siemens Axiom Artis as the angiography machine (Siemens Medical Solutions, Erlangen, Germany).

At arterial endovascular treatment, the brachial artery, popliteal artery, or surgical graft was used as an access route. A 4F micropuncture set (Cook MPIS-401-U, Bloomington, IN, USA) was used to access the brachial artery or popliteal artery under sonographic guidance. An $18 \mathrm{G}$ needle and 0.035 -in. wire set were used to create a surgical graft access. All procedures were performed when the patient was under anesthesia with prilocaine (Citanest 2\%, $20 \mathrm{mg}$, AstraZeneca PLC, England). Heparin was administered as a bolus dose of 5,000 IU and as an infusion dose of $1,000 \mathrm{IU} / \mathrm{h}$ for $12 \mathrm{~h}$. The activated clotting time measurement was not used.

Subsequent to arterial endovascular treatment, the vascular sheath was removed and the EVCD plug was deployed. EVCD deployment was compatible with the thickness of the vascular sheath. There are two main technical points related to the appropriate extravascular application of the plug: (1) arterial pulsatile flow discontinuation, which shows that the device is in the extravascular area, and (2) conversion of the white marker into the black marker on the screen of the device.

At the end of the procedure, manual compression was performed at least for $5 \mathrm{~min}$. If there was no hematoma and hemostasis maintained within $5 \mathrm{~min}$, immobilization was recommended for $1 \mathrm{~h}$. If there was hematoma or if hemostasis was not maintained within $5 \mathrm{~min}$, manual compression was resumed. Subsequently, compression bandaging was applied and immobilization for $5 \mathrm{~h}$ was suggested.

\section{Follow-up}

Physical examination and Doppler ultrasonography (Siemens Acuson Antares ultrasound system, Siemens
Medical Solutions, Erlangen, Germany) were performed within $24 \mathrm{~h}$ of the procedure. In Doppler ultrasonography, access artery, pseudoaneurysm, arteriovenous fistula, and hematoma were investigated. In addition, the findings of thrombosis and embolization were noted.

\section{Analysis}

Technical success was defined as the release of the plug without any major complications. Procedural success was defined as the maintenance of hemostasis with manual compression within 5 min of EVCD deployment without any major complications or the need for a compression bandage.

Major complications were defined as in the ECLIPSE study. They were: (1) hemorrhage that required surgical or non-surgical vascular closure processes or blood transfusion, (2) infections that required treatment with antibiotics, (3) acute ischemia symptoms in the ipsilateral area related to VCD, and (4) nerve injuries that were permanent or required medical intervention [2].

Minor complications were defined as follows: (1) pseudoaneurysm, (2) arteriovenous fistula, (3) $>6 \mathrm{~cm}$ ecchymose or hematoma, and (4) recurrent hemorrhage that required hemostatic treatment [2].

\section{Results}

We performed 13 procedures in 11 patients [ 4 women and 7 men; median age: 65 years (range: $48-87$ years)] who underwent arterial endovascular treatment with EVCD due to peripheral arterial disease. Three procedures were in the upper extremity and 10 were in the lower extremity. The brachial artery $(n=5)$, popliteal artery $(n=4)$, or polytetrafluoroethylene (PTFE) graft $(n=4)$ was used to achieve extra femoral arterial puncture (Table I). A 5F sheath was used in 11 procedures and a $6 \mathrm{~F}$ sheath was used in two procedures. Acetylsalicylic acid and clopidogrel were used in 10 procedures, acetylsalicylic acid only was used in 2 procedures, and enoxaparin was used in 1 procedure.

Technical success and procedural success were achieved in 12 out of 13 procedures. In all cases, EVCD release in the extravascular space was successful in brachial arterial, popliteal arterial, and surgical bypass graft punctures and following the procedure, hemostasis was maintained within $5 \mathrm{~min}$. Surgical bypass graft punctures were performed in three femoropopliteal and one aortofemoral subcutaneous bypass PTFE graft.

The only procedure, which proved to be unsuccessful, was brachial artery closure in Patient no. 4. In this case, hemostasis was maintained with manual compression within $5 \mathrm{~min}$. However, a profound hematoma $(10 \mathrm{~cm}$ in diameter) was observed approximately $12 \mathrm{~h}$ later. 
Table I Patients' characteristics

\begin{tabular}{|c|c|c|c|c|c|c|}
\hline $\begin{array}{l}\text { Procedure } \\
\text { no. }\end{array}$ & Arterial access & $\begin{array}{l}\text { Exoseal French } \\
\text { size }(F)\end{array}$ & $\begin{array}{l}\text { INR value } \\
(0.8-1.1)\end{array}$ & $\begin{array}{l}\text { Procedural } \\
\text { success }\end{array}$ & $\begin{array}{l}\text { Success of the } \\
\text { technical device }\end{array}$ & Complication \\
\hline I & Brachial artery & 5 & 1.2 & + & + & - \\
\hline II & Brachial artery & 5 & 1.2 & + & + & - \\
\hline III & Brachial artery & 5 & 1 & + & + & - \\
\hline IV & Brachial artery & 5 & 1.7 & - & - & $\begin{array}{c}\text { Major } \\
\text { complication }\end{array}$ \\
\hline $\mathrm{V}$ & Brachial artery & 5 & 2.7 & + & + & $\begin{array}{c}\text { Minor } \\
\text { complication }\end{array}$ \\
\hline VI & Popliteal artery & 5 & 1.5 & + & + & - \\
\hline VII & Popliteal artery & 5 & 0.8 & + & + & - \\
\hline IIX & Popliteal artery & 5 & 1.1 & + & + & - \\
\hline IX & Popliteal artery & 5 & 1 & + & + & - \\
\hline $\mathrm{X}$ & $\begin{array}{l}\text { Surgical bypass } \\
\text { graft }\end{array}$ & 5 & 0.8 & + & + & - \\
\hline XI & $\begin{array}{l}\text { Surgical bypass } \\
\text { graft }\end{array}$ & 5 & 1.1 & + & + & - \\
\hline XII & $\begin{array}{l}\text { Surgical bypass } \\
\text { graft }\end{array}$ & 6 & 0.7 & + & + & - \\
\hline XIII & $\begin{array}{c}\text { Surgical bypass } \\
\text { graft }\end{array}$ & 6 & 0.8 & + & + & - \\
\hline
\end{tabular}

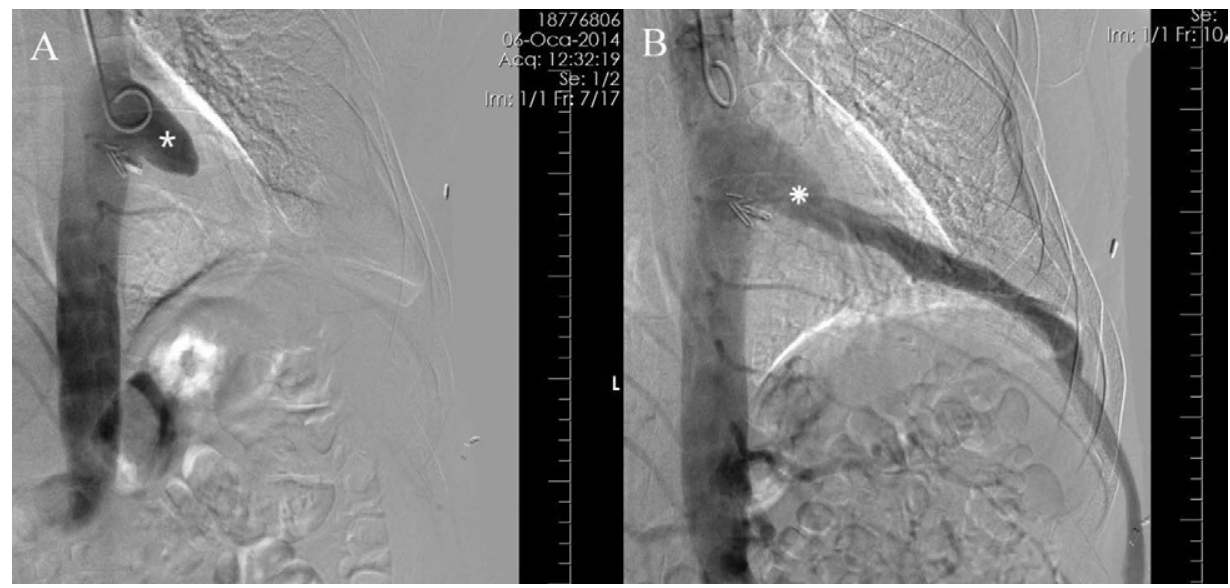

Fig. 1. (A) Brachial artery angiogram shows a pseudoaneurysm. (B) After balloon expandable covered stent placement, pseudoaneurysm was cured successfully

The hematoma was compressed and a bandage was applied. Nonetheless, the area of hematoma grew; an angiography was performed and pseudoaneurysm was observed. The pseudoaneurysm was treated by covered stent (Fig. 1). That was the only major complication in this study.

Only 1 out of 13 procedures led to a minor complication in a patient (Patient no. 5) who suffered from acute critical limb ischemia. The patient had initially presented with sudden cold feet. The patient had a history of
Leriche syndrome and a bypass operation, and the patient was using warfarin as an anticoagulant. International normalized ratio (INR) was 2.7, which was over the upper normal limit. Computed tomography angiography was performed, which showed occlusion in the aortofemoral subcutaneous bypass. Thus, an arterial endovascular treatment was immediately planned whereby we accessed the brachial artery owing to occlusion of both femoral arteries. We did not access the radial artery because of the possibility of mechanic thrombectomy. 
The thoracic angiogram showed thrombo-occlusion of the graft in the patient. An infusion catheter was inserted (Cragg-McNamara; ev3 Endovascular Inc., Plymouth, Minn or Unifuse; Angiodynamics, Latham, NY, USA). Tissue plasminogen activator (Actilyse; Boehringer Ingelheim, Ingelheim, Germany) was given, $8 \mathrm{mg}$ by bolus and $12 \mathrm{mg}$ by infusion within $12 \mathrm{~h}$. After $24 \mathrm{~h}$, control angiography demonstrated resolution of the thrombus. The vascular sheath was removed and EVCD was used. Hemostasis maintained within $5 \mathrm{~min}$. Nevertheless, pseudoaneurysm was revealed in the control Doppler ultrasonography within $24 \mathrm{~h}$. This area was treated completely with thrombin injection under sonographic guidance.

Hemostasis blood parameters were elevated in 5 out of 13 procedures. Although the INR value exceeded the upper normal limit in these cases, we did not normalize the elevated blood parameters before endovascular treatment as these patients had acute cutaneous limb ischemia, which urgently required endovascular treatment.

\section{Discussion}

VCDs decrease compression time, time to ambulation, and patient discomfort. The efficiency and reliability of VCDs have been proven in the literature [3-5]. EVCD was introduced to the medical community in 2010 and is based on the release of polyglycolic acid plug absorbable within 3 months. The device is designed to release the plug into the extravascular area. In interventional radiological treatments, the common femoral artery is generally used as the vascular access route. However, different puncture sites can be necessary, especially in patients with peripheral arterial disease such as those in this study. Obesity and angulated aortic bifurcation are other indications for extrafemoral access $[7,8]$. In this study, we aimed to present our experience of using EVCD to close extrafemoral routes that were implemented during arterial endovascular treatment.

Most recent studies on EVCD with regard to superficial femoral artery antegrade punctures have shown that this device is reliable and successful [9-11]. In 2014, Pieper et al. [6] published an initial study on using EVCD to achieve extrafemoral access site closure [6]. In this study, technical success and procedural success were achieved in 12 out of 13 cases. The only unsuccessful case was related to a minor complication of hematoma less than $3 \mathrm{~cm}$. Although this is the first study in a limited number of patients, it showed that EVCDs can be used outside the femoral artery. This study adds to the findings of the Pieper et al.'s study, supporting the potential use of EVCDs outside the femoral artery.

The brachial artery has been reported as the most common site of extrafemoral access for endovascular intervention. The success of suture-closed, clip-based, and collagen-based devices in regard to this access route was reported to be $>90 \%, 100 \%$, and $96.9 \%$, respectively. In these studies, minor and major complications were rare [12-16]. Hematoma was reported as a minor complication. In this study, there were four brachial artery accesses. One procedure was not successful and the patient had a major complication. Four procedures were successful, although INR values of patients in all these procedures were increased and one patient experienced pseudoaneurysm as a minor complication.

Although this study did not include procedures involving axillary artery access, the indications for axillary artery access are the same as for brachial artery access. However, axillary artery access is not as reliable as brachial artery access because brachial artery can be compressed using the underlying humerus. The rates of complications, such as nerve damage, are higher with axillary artery access. Often, the reason is ruptured medial brachial fascia resulting from hematoma [17]. Inglese et al. [18] presented their experience on using an 8F collagen-based closure device to close the axillary arterial access route. In all four patients, success was achieved with no complications in the 2-month follow-up. Gonen et al. [19] used a clipbased device in six patients. Hemostasis was not achieved in $2 \mathrm{~min}$ in only one case. In their study, one hematoma $(5 \times 6 \mathrm{~cm})$ and one complaint of slight pain at the puncture site were minor complications.

The first reported instance of using a VCD to close popliteal arterial punctures is in Henry et al. [20] who used a collagen-based VCD. Although their study mainly involved the use of VCD for closing the common femoral artery, VCD was used in three cases with the popliteal artery as an access route. Success was achieved in all three cases with no complications. Subsequently, Hoffman et al. [21] reported one case of popliteal artery closure using a suture-mediated device and success was achieved without any complications in the 3 -month follow-up. Noory et al. [22] presented that clip-based device was used in 28 patients with peripheral artery disease. Technical success was achieved in all patients. There were three small hematomas $(<5 \mathrm{~cm})$ that were minor complications. Only one patient had popliteal artery occlusion as a major complication. To date, Balli et al. [23] presented the largest study on using EVCD for arterial artery closure. In this study, the technical failure rate was $4.3 \%$. There were three minor complications and one major complication. In this study, we used EVCD to close four popliteal arterial routes. Hemostasis was achieved in all cases without any complication.

Pieper et al. [6] were the first to report the use of EVCD to close a venous bypass route. In their study, the same patient underwent three procedures. All procedures were carried out successfully. No complications were reported. Bypass graft puncture is generally avoided as an access route as graft puncture carries a risk of complications, such as rupture, infection, and 
pseudoaneurysm. However, in some cases, it may be vital. Manual compression of graft access requires special attention because the risk of thrombosis in grafts is higher than that in native vessels [17]. In this study, the success of the procedure in all four cases with surgical graft access was achieved with no complication.

This study has some limitations as a result of the EVCD application in a limited number of cases. Finally, this is an initial study and large-scale studies are needed regarding off-label usage.

In conclusion, we present our experience on applying EVCD to close surgical bypass graft, popliteal artery, and brachial artery access routes.

$$
* * *
$$

Funding sources: The authors have no support or funding to report.

Authors' contribution: IC contributed in performing the procedure, drafting and writing of the manuscript, and revision. FN contributed in drafting the manuscript. OK contributed in drafting and writing. OA critically revised the manuscript. BG performed the procedure.

Conflict of interest: The authors declare no conflict of interest.

\section{References}

1. Bell JK, Chalmers N (2012): Sites of arterial access and the role of closure devices in percutaneous arterial interventions. In: Vascular Interventional Radiology. Current Evidence in Endovascular Surgery, ed. Cowling N. Springer, Heidelberg, Germany, pp. 43-51

2. Schrader R, Steinbacher S, Burger W, Kadel C, Vallbracht C, Kaltenbach M: Collagen application for sealing of arterial puncture sites in comparison to pressure dressing: a randomized trial. Cathet Cardiovasc Diagn 27, 298-302 (1992)

3. Schwartz BG, Burstein S, Economides C, Kloner RA, Shavelle DM, Mayeda GS: Review of vascular closure devices. J Invas Cardiol 22 599-607 (2010)

4. Biancari F, D'Andrea V, Di Marco C, Savino G, Tiozzo V, Catania A: Meta-analysis of randomized trials on the efficacy of vascular closure devices after diagnostic angiography and angioplasty. Am Heart J 159, 518-531 (2010)

5. Eggebrecht H, Haude M, Woertgen U, Schmermund A, von Birgelen C, Naber C, Baumgart D, Kaiser C, Oldenburg O, Bartel T, Kroeger K, Erbel R: Systematic use of a collagen-based vascular closure device immediately after cardiac catheterization procedures in 1,317 consecutive patients. Cathet Cardiovasc Interv $57,486-495$ (2002)

6. Pieper CC, Wilhelm KE, Schild HH, Meyer C: Feasibility of vascular access closure in arteries other than the common femoral artery using the ExoSeal vascular closure device. Cardiovasc Interv Radiol 37, 1352-7 (2014)

7. Cordis (2011): Instructions for Use: Cordis Exoseal Vascular Closure Device. Cordis Corporation, Miami Lakes, FL, USA
8. Bachinsky W, Cambier P, Stoler R, Aji J, Rogers JH, Hermiller J, Nair R, Hutman H, Wang H, ECLIPSE Trial Investigators: A randomized comparison of a novel bioabsorbable vascular closure device versus manual compression in the achievement of hemostasis after percutaneous femoral procedures: the ECLIPSE trial (Ensure's Vascular Closure Device Speeds Hemostasis trial). JACC Cardiovasc Interv 2, 785-793 (2009)

9. Hackl G, Gary T, Belaj K, Hafner F, Rief P, Deutschmann H, Brodmann M: Exoseal for puncture site closure after antegrade procedures in peripheral arterial disease patients. Diagn Interv Radiol 20, 426-431 (2014)

10. Rimon U, Khaitovich B, Yakubovich D, Bensaid P, Golan G, Silverberg D: The use of Exoseal vascular closure device for direct antegrate superficial femoral artery puncture site hemostasis. Cardiovasc Intervent Radiol 38, 560-564 (2015)

11. Lupattelli T, Clerissi J, Clerici G, Minnella DP, Casini A, Losa S, Faglia E: The efficacy and safety of closure of brachial access using the AngioSeal closure device: Experience with 161 interventions in diabetic patients with critical limb ischemia. J Vasc Surg 47, 728-782 (2008)

12. Kweon M, Bhamidipaty V, Holden A, Hill AA: Antegrade superficial femoral artery versus common femoral artery punctures for infrainguinal occlusive disease. J Vasc Interv Radiol 23, 1160-1164 (2012)

13. Kulick DL, Rediker DE: Use of the perclose device in the brachial artery after coronary intervention. Catheter Cardiovase Interv 46, 111-112 (1999)

14. Gliech V, Dübel HP, Rutsch W: Suture closure of the brachial artery access site post-coronary catheterization. J Invasive Cardiol 13, $12-14(2001)$

15. Kim A, Fusman B, Jolly N, Feldman T: Percutaneous suture closure for brachial artery puncture. J Interv Cardiol 15, 277-280 (2002)

16. Lee S, Kim CW, Jeon UB: Safety and effectiveness of a circumferential clip-based vascular closure device for hemostasis in off-label applications: Comparison with standard applications. J Korean Soc Radiol 75, 171-176 (2016)

17. Sheth RA, Ganguli S: Closure of alternative vascular sites, including axillary, brachial, popliteal, and surgical grafts. Tech Vasc Interventional Rad 18, 113-121 (2015)

18. Inglese L, Lupattelli T, Carbone GL, Palmisano D, Musto C, Mollichelli N: Axillary artery access for interventional procedures. J Endovasc Ther 11, 414-418 (2004)

19. Gonen KA, Erdoğan C, Hakyemez B: Closure of the axillary artery puncture site with starclose system after endovascular interventions. J Vasc Interv Radiol 25, 640-645 (2014)

20. Henry M, Amor M, Allaoui M, Tricoche O: A new access site management tool: The Angio-Seal hemostatic puncture closure device. J Endovasc Surg 2, 289-296 (1995)

21. Hoffmann K, Schott U, Erb M, Albes J, Claussen CD, Duda SH: Remote suturing for percutaneous closure of popliteal artery access. Cathet Cardiovasc Diagn 43, 477-482 (1998)

22. Noory E, Rastan A, Sixt S, Schwarzwälder U, Leppännen $O$, Schwarz T, Bürgelin K, Hauk M, Branzan D, Hauswald K, Beschorner U, Nazary T, Brantner R, Neumann FJ, Zeller T: Arterial puncture closure using a clip device after transpopliteal retrograde approach for recanalization of the superficial femoral artery. J Endovasc Ther 15, 310-314 (2008)

23. Balli O, Cakır V, Coskun M, Pekcevik R, Gur S: Implementation of the EXOSEAL vascular closure device in the transpopliteal arterial approach. J Vasc Interv Radiol 29, 1-7 (2018) 